\title{
PRESENÇA DA FAMÍLIA NAS UNIDADES DE TERAPIA INTENSIVA PEDIÁTRICA E NEONATAL: VISÃO DA EQUIPE MULTIDISCIPLINAR
}

\author{
Family Presence in the Pediatric and Neonatal Intensive Therapy Unit: \\ The View of the Multidisciplinary Team \\ Presencia de la Familia en las Unidades de Terapia Intensiva Pediátrica y Neonatal: \\ Visión del Equipo Multidisciplinar
}

Rosemeire Cristina Moretto Molina

Luciana Olga Bercini
Patrícia Louise Rodrigues Varela

Sonia Silva Marcon
Sonia Aparecida Castilho

\begin{abstract}
Resumo
0 presente estudo tem por objetivo compreender a visão da equipe multidisciplinar quanto à presença da família nas Unidades de Terapia Intensiva (UTI) pediátrica e neonatal. A pesquisa teve como eixo norteador a abordagem qualitativa. Para a análise e interpretação dos dados, optou-se pela análise de conteúdo. Os dados foram coletados em junho de 2006, por meio de entrevista semi-estruturada junto a 25 profissionais atuantes nas UTI pediátrica e neonatal de dois hospitais na região noroeste do Estado do Paraná. Do discurso destes profissionais, desvelou-se o conflito íntimo vivenciado por cada um com relação à presença da família nas unidades. Conclui-se que o primeiro passo para a mudança e melhor aceitação dos familiares dentro da UTI é sensibilizar os profissionais quanto à importância da presença da família para a criança em momentos de crise, como na hospitalização.
\end{abstract}

Palavras-chave: Cuidado da criança. Unidade de Terapia Itensiva. Relações Profissional-Família.

\section{Abstract}

The present study has the aim to understand the view of a multidisciplinary team as for the presence of family in the Units of Pediatric and Neonatal Intensive Care (ICU). The research has had as a guide axis the qualitative approach. For the analysis and data interpretation, it has been opted for the content analysis. Data were collected in June of 2006 , through a semi-structured interview with 25 professionals in action at the pediatric and neonatal Intensive Care Unit of two hospitals in the northwest area of Paraná State. From the statements of these professionals, the intimate conflict was revealed, lived by each one, regarding the presence of the family in the units. The first step for behavioral changing and better acceptance of parents in the ICU is sensitizing the professionals for the importance of the family into the child's life in moments of crisis, as well as in the hospitalization.

Keywords: Child Care. Itensive Care Units. ProfessionalFamily relations.

\section{Resumen}

El presente estudio tiene por objetivo comprender la visión del equipo multidisciplinar en cuanto a la presencia de la família en las Unidades de Cuidados Intensivos (UCI) pediátricos y neonatal. La investigación ha tenido como eje norteador el abordaje cualitativo. Para el análisis e interpretación de los datos, se optó por el análisis de contenido. Los datos fueron colectados en junio de 2006, por medio de encuesta semiestructurada junto a los profesionales actuantes en las unidades de cuidados intensivos pediátricos y neonatal de dos hospitales en la región noroeste de la provincia de Paraná. Veinticinco profesionales fueron informantes. De los discursos de estos profesionales, se desveló el conflicto íntimo vivido por cada uno com relación a la presencia de la familia en estas unidades. Sensibilizar a los profesionales para la importancia de la familia, en la vida del niño en momentos de crisis, como en la hospitalización es el primer paso parauna mudanza de comportamiento y una mejor aceptación de los familiares dentro de las UCl.
Palabras clave: Cuidado del Niño. Unidades de Terapia Itensiva. Relaciones Profesional-Familia. 


\section{INTRODUÇÃO}

A assistência à criança nos países ocidentais vem sofrendo várias e significativas transformaç̃os, principalmente a partir do fim do século XIX, decorrentes de mudanças na atenção à saúde, no valor e significado que a criança tem para a sociedade e na preocupação com questões relacionadas à humanização da assistência. Até 1930, a assistência de enfermagem à criança hospitalizada tinha a finalidade de prevenir infecções e a transmissão de doenças contagiosas por meio do isolamento rigoroso, privando a mãe e os familiares do contato com a criança e com os profissionais de saúde. ${ }^{1}$

A introdução de terapias antimicrobianas e os avanços tecnológicos possibilitaram a revisão da relação custo-benefício do afastamento dos pais e familiares durante a hospitalização de seus filhos. Concorreram para isto as transformações nos conceitos de criança, compreendida agora como um ser em desenvolvimento não só físico, mas também social, emocional e psicológico.

No Brasil, foi apenas a partir do final da década de 1980 que a família começou a participar do cuidado à criança hospitalizada. São Paulo, através da Resolução SS-165, de 1988, foi o primeiro Estado brasileiro a assegurar o direito aos pais de acompanhar seus filhos durante toda a internação².

0 Estatuto da Criança e do Adolescente (Lei $n^{0} .8069$, de 1990) regulamenta esta situação no país como um todo, pois no artigo 12 é estabelecido que os hospitais devem proporcionar condições para a permanência em tempo integral de um dos pais ou responsável, nos casos de internação de criança ou adolescente $3: 12$.

Em que pese a isso, esta modalidade ainda não é uma realidade em muitas instituições e Estados brasileiros, especialmente nas unidades de tratamento intensivo (UTIs) pediátricas e neonatais, embora a presença da mãe constitua método efetivo para minimizar os traumas psicológicos da hospitalização na criança. ${ }^{1,2}$

Felizmente, essa realidade vem sendo modificada no cotidiano das unidades de tratamento intensivo neonatal (UTINs) e unidades pediátricas de tratamento intensivo (UTIPs), pois vêm ocorrendo mudanças de comportamento dos profissionais envolvidos na assistência, que estão adotando um modelo de assistência centrada na criança e na família, baseado em uma filosofia de assistência moderna. No entanto, por envolver uma complexidade de relações que se estabelecem no ambiente hospitalar, esses profissionais enfrentam enormes desafios ao implantarem esse modelo, principalmente no que se refere à inclusão dos pais no processo de cuidar. ${ }^{4}$

As Unidades de Terapia Intensiva Neonatal (UTINs) e as Unidades de Terapia Intensiva Pediátrica (UTIPs) foram criadas com o objetivo de salvar a vida de crianças em risco iminente de vida, e o desenvolvimento da ciência médica, mediante a realização de procedimentos cada vez mais complexos e por vezes invasivos, aliados à utilização de tecnologias cada vez mais potentes, tem conseguido salvar e prolongar a vida de pacientes de todas as idades.

Essas unidades exigem de toda a equipe um preparo que sustente a complexidade das atividades desenvolvidas. 0 conhecimento científico e a habilidade técnica são características essenciais para o rigoroso controle das funções vitais na tentativa de reduzir a mortalidade e garantir a sobrevivência dos recém-nascidos e das crianças em risco de vida. ${ }^{5}$

Não obstante, os profissionais atuantes nas UTIs necessitam, além do conhecimento científico e da habilidade técnica, buscar conhecimentos para realizar intervenções também junto às famílias das crianças hospitalizadas. A adoção de alguns modelos teóricos para abordagem à família, como 0 Modelo Calgary de Intervenção, o Modelo de Crenças e o Modelo de Resiliência Familiar, podem subsidiar a atuação dos profissionais junto às famílias, ${ }^{6}$ de modo a auxiliá-las no enfrentamento da doença do filho, permitindo-lhes uma melhor compreensão da doença e da hospitalização da criança.

Ademais, a instrumentalização da equipe também se dará a partir do uso de algumas práticas cotidianas no ambiente de trabalho com vistas ao desenvolvimento de competências comunicativas e de trabalho em equipe. Isto, associado a uma predisposição dos profissionais envolvidos a valorizar a familia como foco da assistência, promoverá um cenário de interação de diferentes pessoas, conceitos, valores e culturas no qual cada ator se diferencia e se reconhece no outro, a partir de dinâmicas que possibilitam falar, escutar, sentir, indagar, refletir e aprender a pensar ${ }^{7}$

Diante do ambiente frio e hostil da UTI, a inclusão da família no cuidado à criança exige que os profissionais estejam abertos e atentos às interações e ao impacto das vivências e conheçam dinâmicas e formas diversas de adaptação. A união da tecnologia e do cuidado humanizado transforma um lugar de dor e sofrimento num ambiente capaz de inspirar esperança em um futuro no qual a criança e seus pais tenham uma vida digna. Compreender as condições da criança e dos pais não é suficiente, é preciso buscar a superação das adversidades decorrentes do processo de doença e hospitalização 8,9 .

Os pais percebem a hospitalização do filho através da interação com os membros da equipe de saúde e do cuidado prestado ao filho. Valorizam a tecnologia e a dedicação dos profissionais, mas, acima de tudo, as atitudes de respeito e consideração, julgando-as indispensáveis na relação interpessoal. ${ }^{9}$

A permanência dos pais em tempo integral no ambiente hospitalar, sua participação no cuidado e a natureza das relações entre crianças, pais e profissionais têm desencadeado novas formas de organização da assistência à criança hospitalizada. Assim, torna-se necessário dirigir o olhar para a família como objeto de cuidado, num processo de relações e intervenções para além do cuidado clínico. ${ }^{4}$

Mudar a perspectiva tradicional de cuidado centrado na doença para uma abordagem cujo núcleo está na criança e na família dentro da UTI pode não ser algo fácil. É preciso derrubar as barreiras, eliminar a indiferença, fazer-se presente - não pela imposição de rotina, mas pela atitude de interesse e de preocupação. Tornar-se empático - imbuir-se do outro; identificar-se com o outro - essa é a maneira mais humana e capaz de perceber os tantos outros que cada um de nós possui, espelhados naquele próximo com que se atua., ${ }^{5,9}$

A família apresenta, a exemplo de seus filhos, a necessidade de também ser atendida e cuidada. É preciso lembrar que na 
internação pediátrica não temos somente um paciente, mas o binômio mãe-filho. 0 cuidado com a criança implica necessariamente considerar sempre esta perspectiva, em que o bem-estar de um afeta diretamente a condição do outro e 0 bem-assistir à criança perpassa a orientação e o envolvimento pleno da família neste processo. Neste contexto, cuidados intensivos que visem à estabilização hemodinâmica da criança sem desumanizar a assistência ou desconsiderar a importância da família para a recuperação da criança são atitudes que devem ser tomadas pelos profissionais cuidadores atuantes nestas unidades.

Diante do exposto, definiu-se como objetivo deste estudo compreender a visão da equipe multidisciplinar quanto à presença da família nas UTIs pediátricas e neonatais.

\section{METODOLOGIA}

Trata-se de um estudo descritivo com abordagem qualiquantitativa e tem como matéria principal de investigação a palavra expressa pelos profissionais de saúde entrevistados. A metodologia escolhida justifica-se por ser capaz de aprofundar a complexidade de fenômenos, fatos e processos particulares e específicos de grupos delimitados em extensão e passíveis de ser abrangidos intensamente. ${ }^{11}$

0 estudo foi desenvolvido na UTIN e UTIP do Hospital Universitário Regional de Maringá (HURM), e na UTIN da Santa Casa de Paranavaí, ambos os municípios localizados na Região Noroeste do Paraná, com 288.465 e 80.000 habitantes, respectivamente. ${ }^{12}$

0 HURM é um hospital-escola, público, de médio porte, com 120 leitos, constituindo-se em referência para o município de Maringá e demais municípios da $15^{\text {a }}$ Regional de Saúde. A sua UTIN foi inaugurada em fevereiro de 1998 e dispõe de seis leitos para o atendimento de recém-nascidos (RN), e a UTIP foi inaugurada cinco anos após e dispõe de seis leitos para internação de crianças acima de 28 dias de vida a menores de 14 anos.

A Santa Casa de Paranavaí é um hospital de médio porte, com 110 leitos, que atende usuários do Sistema Único de Saúde, vários convênios e particulares, sendo uma instituição de referência para Paranavaí e demais cidades da $14^{\mathrm{a}}$ Regional de Saúde. Sua UTIN foi inaugurada em novembro de 2005 e dispõe de seis leitos para a internação de RNs.

Embora o número de leitos seja o mesmo, os sistemas de funcionamento destas unidades são diferentes. A UTIP do HURM e a UTIN da Santa Casa são rígidas quanto ao horário de visita: ambas estabelecem dois horários de uma hora cada, sendo um no período vespertino e o outro no período noturno.

Na UTIP, é permitida a entrada dos pais nos horários de visita e de mais um visitante, de forma alternada. Em algumas situações, após avaliação da equipe, é liberada a permanência de um acompanhante junto à criança, de preferência o pai ou a mãe.

Já na UTIN da Santa Casa de Paranavaí, os pais podem entrar juntos ou alternadamente, dependendo do número de crianças. Conforme a patologia da criança, a mãe é estimulada a segurar o neonato. Na UTIN do HURM, os pais podem entrar em qualquer horário no período das $08 \mathrm{~h} 00 \mathrm{~min}$ às $22 \mathrm{~h} 00 \mathrm{~min}$ e, inclusive, permanecer junto ao RN durante todo o horário de visita a eles destinado, e, se possível, realizar o contato pelea-pele como forma de ofertar acalento, segurança, afeto e carinho.

A população de estudo foi constituída pelos profissionais: médicos, enfermeiros, técnicos ou auxiliares de enfermagem, atuantes nestas três unidades. Atualmente, as equipes estão constituídas da seguinte forma: a UTIN (HURM) conta com 10 enfermeiros, 8 técnicos de enfermagem, 2 auxiliares de enfermagem e 14 médicos; a UTIP (HURM), com 10 enfermeiros, 9 técnicos de enfermagem, 1 auxiliar de enfermagem e 7 médicos; e a UTIN da Santa Casa de Paranavaí, com 4 enfermeiros, 6 técnicos de enfermagem, 2 auxiliares de enfermagem e 9 médicos.

Osinformantesforam selecionados, aleatoriamente, numa proporção de $30 \%$ de cada categoria profissional, totalizando 25 profissionais.

Os dados foram coletados em junho de 2006 por meio de um questionário auto-aplicável, respondido no próprio local de trabalho, tendo os pesquisadores ficado à disposição para esclarecimentos durante todo seu preenchimento. 0 instrumento utilizado na coleta de dados foi elaborado pelas próprias autoras, com base nos objetivos do estudo, e constituiuse de um questionário do tipo misto, com 18 questões, que abordavam, além da caracterização da amostra, a vivência no processo de acolhimento da família nas UTINs e na UTIP.

Para a análise e interpretação dos dados, optou-se pela análise de conteúdo ${ }^{13}$. Na apresentação dos resultados, os discursos dos sujeitos estão identificados com as iniciais da profissão: M para médico, E para enfermeiro e T para técnico e auxiliar de enfermagem, seguidos do número da participação da pesquisa.

A apresentação, neste formato, procurou garantir, entre outros aspectos, a preservação das identidades dos sujeitos investigados, cuja participação atendeu às especificações da Res. 196/96-CNS, acerca de pesquisas envolvendo seres humanos. 0 projeto foi aprovado pelo Comitê de Ética em Pesquisa da Universidade Estadual de Maringá (Parecer $n^{0}$. 083/2006).

\section{RESULTADOS E DISCUSSÃO}

Os 25 participantes (sete enfermeiros, nove médicos e nove técnicos), em sua maioria, eram do sexo feminino, casados, com idade média de 34 anos, e possuíam entre 1 e 4 filhos. Quanto à escolaridade, 17 tinham curso superior, e oito, 0 ensino médio; destes profissionais, sete eram formados havia menos de 5 anos; quatro tinham entre 5 e 10 anos, e 11, entre 10 e 20 anos de exercício profissional; quatro deles tinham menos de 5 anos de atuação em cuidados intensivos pediátricos e/ou neonatais, 20 tinham entre 5 e 10 anos, e um, mais de 10 anos. Dentre os profissionais de nível superior, um estava cursando o doutorado (médico), dois eram mestrandos (enfermeiro e médico) e 15 possuíam título de especialista, sendo sete em UTI pediatria/neonatal ou em pediatria.

Sobre a presença da família: a importância do vínculo afetivo

A criança enferma está exposta a inúmeras situações desagradáveis, que aumentam à medida que seu estado de saúde se agrava, pois, submetida a vários procedimentos dolorosos, ela se torna insegura e angustiada. ${ }^{14}$ 
0 estresse da criança é inevitável durante o período de internação na UTI, visto que vários são os fatores causadores deste distúrbio, entre os quais o medo, a dor, os longos períodos de vigília, a mudança do ambiente e a ausência da família. Os resultados encontrados mostram que os profissionais têm conhecimento do estresse e do sofrimento que a criança vivencia diante da à internação, pois a mudança de ambiente lhe causa desequilíbrio emocional, principalmente quando não pode compartilhar com a família esta nova situação vivencial.

A retirada da criança do ambiente em que ela vive gera angústia e dor, que a criança tem dificuldade em trabalhar. (M 6)

Em contrapartida, a presença da família, em especial a da mãe, geralmente promove e mantém a inter-relação criança/ família/equipe, neutraliza os efeitos negativos decorrentes da separação, melhora sua adaptação ao hospital, facilita a aceitação do tratamento e ameniza os fatores estressantes da doença, dos procedimentos e da hospitalização. ${ }^{14,15}$

Estes benefícios são percebidos pela maioria dos profissionais em estudo, e seus discursos demonstram uma coerência com o que tem sido divulgado na literatura:

Favorecer a manutenção do vínculo mãe e filho ou pai e filho contribui para minimizar o estresse da criança frente à internação (E 3).

A presença da família é muito importante em nossa vida e, sobretudo, nos momentos mais difíceis... Ela pode ser extremamente positiva tanto para a criança hospitalizada quanto para a própria família, que talvez se sinta mais segura, podendo acompanhar o tratamento de seu filho (T 4).

Fundamental para a recuperação da criança, para 0 apoio, para se sentir querida dentro do "aquário" onde ela está (M 12).

Os profissionais relataram que, na maioria das vezes, são favoráveis à presença da família no dia-a-dia da UTI, pois observam que os pais promovem melhor resposta ao tratamento, tornando as crianças mais calmas. A presença familiar fortalece o vínculo afetivo e confere maior tranqüilidade e segurança ao trinômio pai-mãe-filho. Além disso, eles vêem a família como facilitadora do inter-relacionamento entre a criança e a equipe.

Estabelece melhor o vínculo, o bebê se torna da famillia, e não um desconhecido (M 14).

Na neonatal, pela dificuldade do vínculo $R N$ e pais, o contato e a aproximação são fundamentais para segurança e ciência dos pais sobre a gravidade ou situação do RN; na Pediátrica, a presença dos pais é fator decisivo na intermediação entre doente e a equipe, além de fortalecer emocionalmente a criança (M 6).

O bebê, ao ter contato com a mãe/família, fica mais tranqüilo e ganha mais peso (E 25)

Os informantes evidenciaram a preocupação em proporcionar aos pais a oportunidade de desenvolver ou estreitar o vínculo afetivo com seus filhos durante o período da hospitalização, por meio do toque, do aconchego e da aproximação familiar.
Acreditamos que nós, profissionais, devemos manter o mais próximo possível o entrosamento familiar, principalmente no universo infantil, uma vez que a presença dos pais, como é sabido, contribui positivamente no prognóstico das crianças (E 3).

É fundamental, a recuperação do $R N$ é mais precisa, pois onde há toque, voz e aconchego, a recuperação é mais rápida. (T 11)

Por estes relatos, percebeu-se que há uma sintonia de pensamentos entre as diversas categorias de profissionais que atuam nas unidades de estudo, quanto à importância da participação da família durante a hospitalização da criança.

\section{Comportamento do profissional perante a família}

No que diz respeito à postura do profissional diante da família, notou-se que a maioria dos profissionais, cada um a seu modo, busca acolher da melhor forma possível os familiares, porém evita aproximação maior ou envolvimento emocional com a família, no intuito de se proteger contra o sofrimento gerado pelo adoecimento da criança. Ao se manifestarem como se comportavam diante da família, os profissionais apresentaram os seguintes depoimentos:

Procuro ser solidária, mas, na maioria das vezes, não deixo o lado afetivo me abalar emocionalmente (E 3).

Se os pais estão chorosos ou desesperados com o estado da criança eu evito contato para poupar-me sentimentalmente (M 6).

Não podemos nos envolver muito, fica muito triste (T 11).

A ansiedade, a angústia e o sofrimento dos pais "mexem" com alguns profissionais, que apresentam dificuldades em lidar com situações dolorosas quando são portadores de más notícias. Por esta razão, muitos deles esclarecem dúvidas e orientam apenas na medida do necessário, o que, por conseguinte, reduziu a comunicação e as chances da troca de conhecimentos e da interação efetiva. A comunicação entre os profissionais de saúde e os pais dos bebês apresenta-se quase sempre como um monólogo: apenas uma parte fala (os profissionais) e a outra escuta e acata (pais) ${ }^{16}$. As narrativas abaixo evidenciam o relacionamento impessoal dispensado pelo profissional às famílias.

Tenho dificuldades, algumas sobre o manejo dos pais, outras sobre como abordá-los no momento e pósintercorrências (T 7).

Dou informações mínimas necessárias e indispensáveis (E 17).

Informo como a criança passou o dia anterior e sua evolução desde a internação (M 23).

No entanto, quando há envolvimento emocional com a família, os profissionais se sensibilizam com o sofrimento alheio, mostram-se mais solidários e humanos, tentam compreender a situação vivencial da criança e da família, tornam-se empáticos e, a partir da compreensão da dimensão do sofrimento, buscam maneiras de amenizar a tristeza e a 
angústia de ambos, planejam intervenções práticas para ajudar os pais e outros familiares a compreenderem o processo doloroso da internação.

Eu me sinto muito triste, imagino se fosse eu que estivesse passando por essa situação (M 10).

Fico sem saber o que fazer. Chamo a psicóloga, se a mãe não está presente telefono para ela comparecer à UTI. Chamo o médico para conversar e também converso. Solicito que outro acompanhante fique com a mãe (E 25).

É necessário planejar intervenções para ajudar os familiares a lidarem com o problema (E 13).

Pelos depoimentos, percebem-se dois tipos de comportamento dos profissionais perante a família da criança submetida a tratamento intensivo: enquanto alguns se envolvem emocionalmente, colocando-se até no lugar da família, outros assumem postura de não-envolvimento ou envolvimento parcial como forma de autopreservação emocional.

\section{Ansiedade dos pais: interferência nos cuidados da criança}

Quando questionados sobre a existência de pontos negativos com relação à presença da família na UTI, em sua maioria os entrevistados revelaram que sentem dificuldades diante dos familiares e ficam incomodados com a presença deles, especialmente quando existem interferências ou questionamentos em relação às condutas e procedimentos realizados pela equipe.

A família interfere nos cuidados da criança (M1).

Não gosto quando a família interfere na conduta da equipe médica e de enfermagem (T 4).

[...] Há temor dos pais pelos procedimentos invasivos realizados na UTI (E 15).

Os familiares ficam questionando a todo o momento (M23).

Os profissionais relataram ainda que alguns pais ficam muito ansiosos e preocupados durante a hospitalização do filho e que o ambiente da UTI contribui para aumentar 0 estresse e a ansiedade, a ponto de os pais atrapalharem a rotina e a dinâmica da unidade.

Pais emocionalmente instáveis podem não suportar o ambiente estressante de uma UTI ( M 1).

Ansiedade em alto grau causa tumulto na rotina do serviço (M 12).

A presença dos pais na UTI implica o desenvolvimento de certas ações pela equipe que interferem no andamento do serviço e dos cuidados, já que, em virtude da proximidade com o filho, alguns procedimentos precisam ser realizados novamente ou o atendimento da criança precisa ser atrasado. Neste contexto, os autores percebem, por exemplo, que os pais colaboram quando não criam clima de confronto entre o que desejam e o que vivenciam. ${ }^{17}$

As narrativas dos profissionais evidenciam que quando os pais não estão bem preparados, podem atrapalhar as rotinas e reduzir os benefícios da presença da família junto às crianças e aos RNs.
0 que pode pesar de forma negativa é a falta de orientação para algumas famílias (M 8).

Há despreparo dos familiares para uma criança sob cuidados intensivos (E 17).

Déficit de conhecimento relacionado à assistência. Conflito relacionado com a limitação de dispensar cuidados, temor de manipular o paciente devido aos equipamentos (E 13).

É compreensível que os profissionais vivenciem momentos de conflitos íntimos com relação à permanência dos pais na UTI, visto que a inclusão desse novo elemento (os pais) no cuidado e no interior das UTI é algo novo, incipiente, que precisa ser trabalhado junto à equipe, não se podendo esquecer que cada profissional traz consigo seus conceitos de família, seus valores, suas crenças e sua cultura, os quais, de forma direta ou indireta, influenciam na aceitação de compartilhar com a família o ambiente que antes era somente seu.

Inclusão da família: dificuldades de adaptação a essa nova realidade

Embora seja estabelecida por lei, a presença dos pais durante a internação do filho ainda não é uma realidade na maioria das instituições, principalmente nas UTIs, visto que muitos profissionais desconhecem ou desrespeitam a lei. No presente estudo, nenhum dos participantes mencionou estar previsto em lei esse direito da criança.

Os sujeitos, na grande maioria, se contradisseram quanto à presença da família na UTI, pois, apesar de considerarem importante a participação da família, expressaram em seus relatos certa resistência à presença da família em período integral junto à criança e argumentaram que há falta de estrutura física para acomodar adequadamente os pais e que estes atrapalham a dinâmica de trabalho institucional:

Adequada à permanência dos pais, desde que a unidade tenha condições estruturais e físicas e a família também tenha condições psicológicas e emocionais. Acho que a unidade deve ser franqueada para a entrada dos pais e avós de forma organizada e que não interfira nos horários críticos dos trabalhos (M 1).

Que tivesse um ambiente separado para as mães e com livre acesso, porém com regras ( E 3).

É importante frisar que a equipe necessita de um mínimo de privacidade em UTI (M 14).

Estes relatos corroboram o que já tem sido identificado, ${ }^{2}$ ou seja, que a permanência da família durante a hospitalização de um filho não apenas implica mudanças na rotina hospitalar, nos aspectos referentes à planta física, mas também interfere na trama de relações sociais complexas e cristalizadas presentes nas instituições onde os pilares ainda são a burocracia, o poder, a hierarquização, a rigidez e a administração não participativa, geralmente.

Em alguns depoimentos, percebeu-se como a rigidez da estrutura hospitalar direciona as atitudes dos profissionais e 0 poder que eles exercem sobre a família da criança hospitalizada. 
Necessário permanecer, porém não no momento da manipulação da criança. A família fica de fora, mas o apoio é essencial sempre (M18).

Acredito que se deva elaborar um manual de normase rotinas a serem explanadas para o familiar no momento da internação para que se possa manter um ambiente agradável para ambos sem interferir na assistência (E 3).

Não funciona em casos graves, pela dificuldade de lidar com as emoções dos pais e com o aparato que cerca a criança, pela fragilidade da situação (M12).

Concordo com a presença durante o dia sim, mas no período noturno, não (M12).

A importância da família no processo de restabelecimento da criança é algo indiscutível, e o acolhimento da família pelos profissionais atuantes nas UTINs e na UTIP é somente uma questão de tempo e de adaptação.

É notório que, tanto para as crianças quanto para seus pais, existe a sensação de segurança, diminuição da ansiedade e angústia quando pais e filhos permanecem juntos no ambiente hospitalar (M 1).

Talvez o aspecto mais importante seja a preparação psicológica da equipe de profissionais que estarão em contato constante com essas famílias (T 4).

É necessário que o acompanhante tenha horários para refeição e descanso, mas a presença da família junto à criança transmite segurança e conforto, dando-lhe bom equilíbrio emocional (E 13).

A presença da família, além de possibilitar condições emocionais mais satisfatórias para ambas, tem uma série de outras vantagens: cria relacionamento mais próximo e intenso com a equipe, é fonte direta de informações sobre a evolução da doença, previne acidentes com a criança, é fonte de afeto, segurança e serve de mediadora e facilitadora da adaptação da criança ao hospital. ${ }^{2}$

\section{Modelo assistencial centrado na criança e na família: ampliação do foco de cuidado}

Toda mudança gera alteração de comportamento, desconforto, dúvida, dificuldade de adaptação, conflito e medo do novo. Os relatos dos sujeitos evidenciaram que o modelo de assistência centrado na criança e na família é interessante, embora seja um assunto pouco conhecido entre eles.

As dificuldades de compreensão e adaptação a esse novo modelo assistencial advêm do modelo de assistência estabelecido e até então adotado na maioria das instituições brasileiras, que prioriza o cuidado centrado apenas nas necessidades da criança. ${ }^{6}$

A idéia de ter que dividir espaço com a família gera medo e ansiedade na equipe, pois esta sabe que é preciso reorganizar a dinâmica do trabalho e ampliar o foco de cuidado, visto que também a família, a exemplo de seus filhos, apresenta a necessidade de ser atendida e cuidada. ${ }^{10}$

A abordagem centrada na criança e na família é o modelo mais recente e o menos encontrado nas instituições hospitalares.
Nesta visão, a internação é encarada não apenas como um agravo psicológico à criança, mas também como possível trauma para a família, que necessita de apoio da equipe multiprofissional. ${ }^{18}$

Ao serem questionados sobre o modelo centrado na criança e na família, os profissionais assim se manifestaram:

Ateoria do modelo éde fato interessante. Cabe às instituições e às suas equipes se prepararem para tal ( $E 3)$.

Absolutamente válido, desde que a familia seja bemestruturada e não transfira a culpa da doença da criança para a equipe (M 8).

Muitas vezes é de difícil aplicação, devido ao grau socioeducacional e cultural dos familiares (E 15).

Em estudo realizado anteriormente, ${ }^{17}$ as enfermeiras relataram que a presença da família em UTI neonatal é benéfica para a criança e para os pais e prejudicial ao serviço, porque atrapalha a dinâmica da unidade. No entanto, no presente estudo, todos os profissionais foram unânimes em afirmar que a presença dos pais junto ao filho internado na UTI é um fator decisivo para otimizar o restabelecimento rápido da criança, sendo este o ponto positivo para que eles amadureçam a idéia de dividir com esse elemento novo (os pais) o espaço que antes era somente deles.

Ótimo, teve um avanço grande em relação à criança, familia e saúde (T 7).

O plano é bom, mas necessita ser incorporado por toda a equipe, o que geralmente não acontece (E 25).

Acho essencial para recuperação da criança (M 21).

Éimportante por valorizar o individuo como ser único e por trazer a familia para mais perto do tratamento (E 15).

Os pais se envolvem mais e, quando saem do hospital, ficam felizes e sentem mais segurança em como cuidar (T 20).

Esse modelo tem sido considerado muito incipiente e fortemente influenciado pela motivação pessoal de cada um. ${ }^{19}$ Os profissionais apontaram para a necessidade de discussões em torno do novo modelo de assistência pediátrica dentro das instituições hospitalares, junto aos profissionais atuantes em unidades pediátricas, principalmente em UTIs, ressaltando a importância do inter-relacionamento entre equipe, criança e família, pois na internação pediátrica hospitalar não temos somente um paciente, mas, sim, o binômio mãe-filho.

É um modelo bastante positivo, pois a criança não pode ser vista separada do seu contexto principal, a família (T 4).

0 que chamou a atenção é que os profissionais expressaram preocupação quanto à permanência voluntária dos pais junto ao filho na UTI, pois compreendem que muitos deles não têm condições de permanecer com seus filhos durante 0 período de internação, visto que são, na maioria, pessoas com condições socioeconômicas desfavoráveis, que têm dificuldade de transporte, moram em outros municípios, não podem se ausentar do trabalho e/ou possuem outros filhos que não têm com quem deixar. 
Penso que seria o modelo ideal, não como forma obrigatória, pois na maioria das vezes não conhecemos a realidade familiar, social destes (E 17).

Precisa existir mais amparo aos pais, principalmente uma casa de apoio (M 19).

Seria ótimo para os pais que têm dificuldade de transporte, mas ao mesmo tempo teriam dificuldade de como deixar seus filhos menores (T.20).

A mãe deve ficar quando tiver vontade; deve ser estimulada, e não obrigada (E 25).

Questões de ordem financeira e, muitas vezes, a preocupação com os irmãos que ficaram em casa são alguns dos muitos entraves que a família enfrenta na hospitalização da criança, ${ }^{20}$ e a situação se agrava quando a mãe precisa deslocar-se de sua cidade para acompanhar o tratamento do filho, pois podem surgir problemas emocionais, sentimentos de medo, solidão e/ou de abandono e ocorrer uma transformação no modo de ser dessa mãe. ${ }^{21}$

0 bem-assistir à criança perpassa a orientação e 0 envolvimento pleno da família neste processo. Adotar cuidados intensivos que visem à estabilização hemodinâmica da criança, sem desumanizar a assistência ou desconsiderar a importância da família para a recuperação da criança, é atitude que deve ser tomada pelos profissionais cuidadores atuantes nestas unidades. ${ }^{10}$

\section{CONSIDERAÇÕES FINAIS}

Esta pesquisa buscou compreender o cotidiano dos profissionais que atuam em unidades de cuidados intensivos, no que tange à presença da família da criança hospitalizada, sua vivência com esse elemento novo (pais), bem como o seu conhecimento sobre o modelo de assistência centrado na criança e na família e os aspectos positivos e negativos da aproximação e envolvimento da equipe com a família.

A realidade observada revela a complexidade e a diversidade de situações enfrentadas envolvendo tanto os profissionais de saúde quanto as famílias das crianças submetidas a cuidados intensivos.

Os relatos dos profissionais explicitaram o conflito íntimo vivenciado por cada um com relação à presença da família na UTI neonatal ou pediátrica, pois ao mesmo tempo em que sentem dificuldades em inserir a família no contexto da unidade, reconhecem o importante papel desempenhado por elas no processo de hospitalização da criança.

0 interessante é que as opiniões dos profissionais pertencentes às diferentes categorias são semelhantes, evidenciando que todos que vivenciam a dura rotina da UTI compartilham dos mesmos sentimentos diante da criança e da família, independentemente da posição que ocupem. De forma geral, todos revelaram, implícita ou explicitamente, a falta de um arcabouço teórico que possa embasar suas condutas junto às famílias, fato que os leva a manifestar dificuldades em aceitar a presença destas em seu ambiente de trabalho.

É compreensível que haja resistência à presença da família em período integral dentro dessas unidades, onde o espaço físico é inadequado para a acomodação dos pais, a proximidade favorece a observação constante da equipe e o envolvimento com os pais é inevitável, além do que o profissional necessita lidar com o medo, o estresse, a angústia e a ansiedade desses familiares, gerados pela internação, pelo sofrimento e pelas incertezas diante da doença da criança.

Para os profissionais da saúde, acolher a família, na UTI ou em qualquer outra unidade de internação neonatal/ pediátrica, não é apenas permitir a entrada e a permanência dos pais ou de um familiar na unidade, mas, sim, estabelecer relação de confiança e sinceridade entre equipe, família e criança; proporcionar meios para a inserção dos pais no processo de cuidado da criança, assumindo a postura de educadores, esclarecendo dúvidas e preparando os pais para o processo de alta hospitalar.

Não podemos deixar de considerar que, no ambiente de UTI, a criança não pode ser vista isoladamente, mas sim como um binômio: mãe-filho. Assim, neste contexto não é apenas a criança que precisa de cuidados da equipe de saúde, mas também a sua família precisa ser acolhida, informada, apoiada, isto é, cuidada.

Sensibilizar os profissionais quanto à importância da família na vida da criança, especialmente em momentos de crise - como na hospitalização - é o primeiro passo para que haja uma mudança de comportamento e uma melhor aceitação da família dentro dessas unidades, não como uma imposição da lei, mas como uma necessidade sentida a partir da revisão de conceitos, valores e atitudes.

Ademais, além de sensibilizar, faz-se mister despertar na equipe o interesse pela busca de conhecimentos teóricos que possam dar respaldo científico e sustentação às mudanças necessárias para melhor cuidar da família da criança hospitalizada.

Assim, com a instrumentalização adequada da equipe multidisciplinar de saúde, de acordo com a realidade de cada serviço estudado, os profissionais que ali atuam, caso queiram vencer as dificuldades de inserção da família na UTI, terão que encontrar seu próprio caminho em busca da assistência à criança e sua família neste cenário complexo de cuidados intensivos. 


\section{Referências}

1. Lima RAG, Rocha SMM, Scochi CGS. Assistência à criança hospitalizada: reflexões acerca da participação dos pais. Rev Latinoam Enfermagem 1999 abr; 7 (2): 33-9.

2. Gomes GC, Erdmann AL. 0 cuidado compartilhado entre a família e a enfermagem à criança no hospital: uma perspectiva para a sua humanização. Rev Gaúcha Enferm 2005 jan/abr; 26 (1): 20-30.

3. Ministério da Saúde (BR).Ministério da Criança/Projeto Minha Gente. Estatuto da Criança e do Adolescente. Brasília(DF); 1991.

4. Collet N, Rocha SMM. Criança hospitalizada: mãe e enfermagem compartilhando o cuidado. Rev Latino-am Enfermagem 2004 mar/ abr; 12 (2): 191-97.

5. Pedroso EG, Bousso RS. 0 significado de cuidar da família na UTI neonatal: crenças da equipe de enfermagem. Acta Sci Health Sci 2004 jan/jun; 26 (1): 129-34.

6. Silveira A0, Ângelo M. Interaction experience for families who lives with their child's disease and hospitalization. Rev Latino-Am Enfermagem 2006 nov/dez; 14(6): 893-00.

7. Silveira LMC, Ribeiro VMB. Grupo de adesão ao tratamento: espaço de "ensinagem" para profissionais de saúde e pacientes. Interface 2005 set/fev; 9 (16): 91-104.

8. Andraus LMS, Minamisava R, Munari DB. Desafios da enfermagem no cuidado à família da criança hospitalizada. Cienc Cuid Saude 2004 maio/ago; 3 (2): 203-08.

9. Cunha MLC. Recém-nascidos hospitalizados: a vivência de pais e mães. Rev Gaucha Enferm 2000; 21 ( $n^{0}$ esp): 70-83.

10. Almeida MI, Molina RCM, Vieira TM, Higarashi IH, Marcon SS. 0 ser mãe de criança depende: realizando cuidados complexos. Esc Anna Nery Rev Enferm 2006 jan/abr; 10 (1): 36-46.

11. Minayo MCS, Coimbra JR, CEA. Editorial. Cad Saude Publica 1993 jul/set; 9 (3): 237-38.

12. Ministério da Saúde.(BR). DATASUS [on-line]. Brasília; c2000. [ citado 19 jun 2007]. Disponível em: http://tabnet.datasus.gov.br/ tabnet/tabnet.htm\#Estat Vitais.

13. Bardin L. Análise de conteúdo. Lisboa (PT): Ed 70; 1977.

14. Ribeiro NRR. A família enfrentando a doença grave da criança. In: Elsen I, Marcon SS, Silva MRS, organizadoras. 0 viver em família e sua interface com a saúde e a doença. Maringá (PR): Eduem; 2004. p.183-98.
15. Oliveira CMM, Almeida BC, Araújo LT, Galvão GTM. Aplicação do processo de relação interpessoal de Travelbee com mãe do recém nascido internado em um unidade neonatal. Rev Esc Enferm USP 2005 jul/ago; 39 (4): 430-36.

16. Gaíva MAM, Scochi CGS. A participação da familia no cuidado ao prematuro em UTI Neonatal. Rev Bras Enferm 2005 out/dez; 58 (4): 444-48.

17. Rossato-Abéde ML, Angelo M. Crenças determinantes da intenção da enfermeira acerca da presença dos pais em unidades neonatais de alto-risco. Rev Latino-am Enfermagem 2002 jan/fev; 10(1): 48-54.

18. Elsen I, Patrício ZM. Assistência à criança hospitalizada: tipos de abordagem e suas implicações para a enfermagem. In: Schmitz EA. A enfermagem em pediatria e puericultura. Rio de Janeiro (RJ): Atheneu; 1989. p. 69-79.

19. Pauli MC, Bousso RS. Crenças que permeiam a humanização da assistência em unidade de terapia intensiva pediátrica. Rev Latino-am Enfermagem 2003 mai/jun; 11(3): 280-86.

20. Dias SMZ, Motta MGC da. Práticas e saberes do cuidado de enfermagem á criança hospitalizada. Cienc Ccuid Saude 2004 jan/ abr; 3 (1): 41-54.

21. Moreno RLR, Jorge MSB, Moreira RVO. Vivências maternais em unidade de terapia intensiva: um olhar fenomenológico. Rev Bras Enferm 2003 mai/jun; 56 (3): 282-87.

\section{Sobre os Autores}

\section{Rosemeire Cristina Moretto Molina}

Hospital Universitário de Maringá. Maringá - PR

\section{Patrícia Louise Rodrigues Varela}

Universidade Paranense - Unipar. Paranavaí - PR

Sonia Aparecida Castilho

Hospital Universitário de Maringá. Maringá - PR

\section{Luciana Olga Bercini}

Universidade Estadual de Maringá. Maringá - PR

\section{Sonia Silva Marcon}

Universidade Estadual de Maringá. Maringá - PR 